ESCOLARIDADE DE CRIMINOSOS

Jilia Diane Martins Boldori ${ }^{1}$

RESUMO: A educação é um direito social e necessita ser garantida a todos, incluindo aqueles que cometeram crimes. Em que pese esta afirmação, dados oficiais demonstram que o nível de escolarização dos encarcerados é baixo. Para alterar este quadro, políticas públicas educacionais para o sistema prisional são criadas. $O$ presente artigo tem como objetivo investigar o grau de escolaridade dos autores de crime de homicídio ocorridos em 2014, nos processos que tramitam perante a primeira vara criminal da comarca de União da Vitória, Estado do Paraná, bem como verificar os benefícios que o ensino universitário proporciona aos autores de crimes. Com a análise dos dados obtidos na pesquisa, foi possível verificar que os autores de crime de homicídio que respondem processo naquela vara não iniciaram sequer o ensino médio, estando muito distantes do ensino universitário.

Palavras chave: Educação. Criminosos. Ensino universitário.

\title{
EDUCATION OF CRIMINALS
}

ABSTRACT: The education is a social right, needs to be guaranteed to all, including those who have committed crimes. Despite this statement, official data show that the level of education of prisoners is low. To change this situation, public educational policies for the prison system are created. This paper aims to investigate the educational level of the crime of murder of authors occurred in 2014, in the proceedings before before the first criminal court of the district of União da Vitória, state of Paraná, and to verify the benefits that university education provides perpetrators of crimes. With the analysis of data obtained in the survey, we found that the perpetrators of the crime of murder answering process that stick not even started high school, being far from the university.

Key Words: Education. Criminals. University education.

\footnotetext{
${ }^{1}$ Advogada Criminalista. Professora do Curso de Direito da Universidade do Contestado, Campus de Porto União. Santa Catarina. Brasil. E-mail: jiliamartins@hotmail.com
} 


\section{INTRODUÇÃO}

O economista Sérgio Boisier (2010) escreve que toda proposta de desenvolvimento, em seus diversos âmbitos, nacional, regional e local, tem como objetivo criar condições para que os indivíduos possam se reconhecer como pessoas humanas e, para que isso ocorra, é importante que este indivíduo seja dotado de dignidade, ou seja, supõe-se a inexistência de carências básicas.

Partindo desse pressuposto, para que o desenvolvimento seja relevante e eficaz, deverá possibilitar aos indivíduos uma existência digna, com a eliminação de carências básicas como alimentação, saúde e educação. Deverá efetivar uma melhoria na qualidade de vida daqueles que pertencem a região em processo de desenvolvimento.

Desta forma, para iniciar um estudo sobre situações que digam respeito ao desenvolvimento regional, é necessário entendê-lo não apenas por um viés econômico. O fator econômico é relevante quando do estudo do desenvolvimento, mas não será o único responsável por este. Neste sentido, Dallabrida, em sua obra "Desenvolvimento Regional: por que algumas regiões se desenvolvem e outras não?" (2001, p.18) esclarece:

\footnotetext{
Primeiro é necessário distinguir crescimento econômico de desenvolvimento. Não existe concordância entre os autores. Uns até consideram crescimento econômico como sinônimo de desenvolvimento. No entanto, para um maior número de autores, o crescimento econômico é condição indispensável para o desenvolvimento, mesmo admitindo não ser condição suficiente.
}

Apresenta-se assim, de forma inequívoca que desenvolvimento não está limitado ao fator econômico. Por mais que uma região seja desenvolvida economicamente, sem que haja bem estar da população, não se poderá falar em desenvolvimento regional.

Sendo a educação uma carência que pode contribuir para que o processo de desenvolvimento de uma região não alcance seus objetivos, políticas públicas educacionais, nos diversos âmbitos, devem prestar-se a alcançar a todos os indivíduos.

A Constituição da República Federativa do Brasil de 1988, no seu artigo quinto, reza que todos são iguais perante a lei, e, no artigo sexto, que a educação é 
direito de todos. Com estas prescrições, fica claro que a educação deve alcançar também aqueles que cometeram crimes, no sentido de buscar concretizar princípios como a dignidade humana, bem como alcançar a ressocialização daquele que cometeu um delito e cumpre pena em estabelecimento penal.

Ocorre que, mesmo sendo a educação um direito de todos, incluído aqui aquele que cometeu um crime e que se encontre segregado, o nível de escolaridade daqueles que se encontram encarcerados é baixo. Por meio dos dados apresentados pelo Ministério da Justiça, é possível verificar que a maior parte destes ainda não completou o ensino fundamental, conforme a tabela que segue.

Quadro 1 - Quantidade de presos por grau de instrução (DEZ/2012)

\begin{tabular}{lrrr}
\hline Categoria: Perfil do Preso & Masculino & Feminino & Total \\
\hline Indicador: Quantidade de Presos por Grau de Instrução & 482,073 & $31,64513,713$ \\
Item: Analfabeto & 26,62 & 1,193 & 27,813 \\
Item: Alfabetizado & 62,323 & 1,779 & 64,102 \\
Item: Ensino Fundamental Incompleto & 219,241 & $12,188231,429$ \\
Item: Ensino Fundamental Completo & 58,541 & 3,634 & 62,175 \\
Item: Ensino Médio Incompleto & 53,45 & 3,32 & 56,77 \\
Item: Ensino Médio Completo & 35,76 & 3,028 & 38,788 \\
Item: Ensino Superior Incompleto & 3,632 & 451 & 4,083 \\
Item: Ensino Superior Completo & 1,8 & 250 & 2,05 \\
Item: Ensino acima de Superior Completo & 120 & 9 & 129 \\
Item: Não Informado & 22,92 & 900 & 23,82 \\
& & & \\
\hline Valor automático de correção de itens inconsistentes - Diferença & $-2,334$ & 4,888 & 2,554 \\
\hline com relação à população carcerária do Estado & & &
\end{tabular}

Fonte: Ministério da Justiça

Buscando superar este quadro de baixa escolaridade, efetivando as disposições constitucionais, levando aos encarcerados a superação desta carência educacional que se revela nos dados do Ministério da Justiça, que lhes impede a existência digna, bem como caminhando no sentido de atender aos objetivos da execução da pena e das propostas de desenvolvimento regional, são elaboradas políticas públicas educacionais específicas aos encarcerados.

Buscando analisar o grau de escolaridade dos criminosos, este estudo está pautado em pesquisa realizada junto a primeira vara criminal da comarca de União da Vitória. Lá foram buscados todos os processos referentes aos crimes de homicídio cometidos durante o ano de 2014, para, então, levantar o número de criminosos com ensino universitário, completo ou não. Após, serão avaliadas as 
vantagens legais dadas aos criminosos que estudam no cárcere, bem como possíveis vantagens decorrentes do ensino superior no cumprimento da pena.

Justifica-se a busca somente por processos de crimes de homicídio por ser considerado o crime mais grave, dentre aqueles constantes no Código Penal, bem como por ser objeto direto de trabalho da pesquisadora. A escolha do local, primeira vara criminal da comarca de União da Vitória, se deu por ser comarca de residência da pesquisadora.

Foram encontrados vinte e sete processos referentes ao crime de homicídio, no ano de 2014. Destes, foram excluídos do levantamento doze processos, uma vez que ainda se encontram em fase de investigação e a autoria do crime ainda não é conhecida. Os quinze resultados restantes integram este levantamento.

\section{CRIME DE HOMICÍDIO}

Segundo o doutrinador André Estefan, em sua obra: Direito Penal: parte geral (2010), a legislação penal não apresenta um conceito de crime, que permita a sua identificação, uma vez que o contido no artigo $1^{0^{2}}$ do Decreto-Lei 3.914/41, denominada Lei de Introdução ao Código Penal, serve apenas para distinguir crime de contravenção penal.

É na doutrina que se encontram os elementos para a conceituação do que se entende por crime. No entender de Monteiro de Barros, na obra também denominada Direito Penal: parte geral (2009), o crime pode ser conceituado sob três aspectos: Pode-se ter um conceito formal, que corresponde a definição fornecida pelo legislador, aquela constante da Lei de Introdução ao Código Penal, que apenas o diferencia das contravenções penais.

É possível, ainda, conceituar o crime levando em conta o seu aspecto material. Neste sentido, Cezar Roberto Bittencourt (2007) o qualifica como um fato humano que lesa os valores ou os interesses da sociedade, exigindo a ameaça da pena. Desta forma, a lesão a bens jurídicos de suma importância para a sociedade, estão definidos como crime na lei penal, que também comina pena à sua prática.

\footnotetext{
${ }^{2} \mathrm{O}$ artigo primeiro do decreto lei conta com a seguinte redação: Considera-se crime a infração penal que a lei comina pena de reclusão ou de detenção, quer isoladamente, quer alternativa ou cumulativamente com a pena de multa; contravenção, a infração penal a que a lei comina, isoladamente, pena de prisão simples ou de multa, ou ambas. alternativa ou cumulativamente.
} 
O conceito mais utilizado na prática penalista é o analítico, que expõe todos os requisitos necessários para a configuração de uma conduta dita criminosa. No que tange ao conceito analítico de crime, definem-o Zaffaroni e Pierangeli (2007) como sendo a conduta humana que se ajusta a algum dos tipos ${ }^{3}$ legais. Com a conduta humana ajustada a algum dos tipos penais tem-se a tipicidade. Porém, a presença de tipicidade ainda não configura a existência de um crime, uma vez que pode existir permissão da própria lei penal para a prática de condutas típicas, estas são as chamadas excludentes de antijuridicidade. Acaso a conduta típica não esteja permitida, dizem Pierangeli e Zaffaroni (2007) que, a conduta é também ilícita, formando o injusto penal.

Por fim, este injusto penal deve ser, necessariamente reprovável, ou seja, é necessário que o autor do delito tivesse possibilidade de agir de outra forma que não o cometimento do crime. Desta forma, o autor do injusto penal é, também, culpável (PIERANGELI; ZAFFARONI, 2007). Se presentes a conduta humana típica, antijurídica e a culpabilidade deste agente, estará formado o crime, dando margem à aplicação da pena.

Para uma melhor compreensão, importante analisar o crime de Homicídio, em sua forma simples bem como sua forma qualificada para que se possa entender seus elementos essenciais.

Inicialmente o crime de Homicídio simples está previsto no Código Penal da seguinte forma:

"Art 121. Matar alguém:

Pena - reclusão, de seis a vinte anos"

Tem-se, como elemento essencial ao crime unicamente o ato de matar um ser humano. É o tipo mais simples do Código Penal, segundo Pierangeli (2007).

Ainda no crime de Homicídio, previsto no artigo 121, do Código Penal, é possível a forma qualificada:

$\S 2^{\circ}$ Se o homicídio é cometido:

I - mediante paga ou promessa de recompensa, ou por outro motivo torpe;

\footnotetext{
${ }^{3}$ Tipo, segundo estes autores, são os elementos da lei penal que individualizam a conduta humana proibida.
}

Ágora: R. Divulg. Cient., v. 21, n. 1, p. 5-23, jan./jun. 2016 (ISSNe 2237-9010) 
II - por motivo fútil;

III - com emprego de veneno, fogo, explosivo, asfixia, tortura ou outro meio insidioso ou cruel, ou de que possa resultar perigo comum;

IV - à traição, de emboscada, ou mediante dissimulação ou outro recurso que dificulte ou torne impossível a defesa do ofendido;

$\checkmark$ - para assegurar a execução, a ocultação, a impunidade ou vantagem de outro crime:

Pena - reclusão, de doze a trinta anos.

$\mathrm{Na}$ figura qualificada do crime de Homicídio, o tipo fundamental, matar alguém, esta acompanhado de circunstâncias elementares, alterando a pena cominada. Segundo entendimento do doutrinador José Henrique Pierangeli (2007), tais elementares podem se dividir em qualificação em razão dos motivos determinantes da conduta do agente criminoso, previstas nos incisos I e II do parágrafo acima descrito; qualificação pelos meios empregados, e pelos modos de execução do crime, previstos nos incisos III e IV do mesmo parágrafo; bem como a qualificação decorrente dos fins pelos quais a conduta criminosa é praticada. Estas qualificadoras integram o tipo penal, ou seja, são-lhe elementos essenciais para que se configure o Homicídio.

Na presente pesquisa, todos os dados levantados dizem respeito ao crime de homicídio, seja na sua forma simples ou tentada. Como trata-se de processos em curso, a investigação acerca da presença dos dados essenciais para a caracterização ainda está em andamento. Desta forma, pode ocorrer que, no fim dos processos pesquisados, haja a absolvição dos acusados, pelos mais diversos motivos.

\section{ASSISTÊNCIA EDUCACIONAL}

O direito à educação enquanto direito humano fundamental é positivado, pela primeira vez, no século XVIII, na Revolução Francesa, com a Declaração dos Direitos do Homem e do Cidadão. No seu artigo Art. XXII assegurava que: A instrução é a necessidade de todos. A seguir, a Declaração Universal dos Direitos do Homem, proclamada pela ONU, em 1948, reafirma, no artigo XXVI, que a instrução será gratuita, pelo menos nos graus elementares e fundamentais (DIAS, 2007).

A Constituição Federal de 1988 coloca a educação como direito social, no seu artigo $6^{\circ}$, onde se dá primazia a este direito. No artigo 205 , a Constituição prescreve 
que a educação é direito de todos e dever do Estado e da família, e, em seguida, no artigo 208 dispõe que o dever do Estado com a educação deverá ser efetivado, entre outros o ensino fundamental, obrigatório e gratuito, inclusive para os que a ele não tiveram acesso na idade própria (OLIVEIRA, 1999).

Esta é a primeira novidade do texto constitucional com relação à educação, quando garante acesso a este direito aos que não tiveram acesso a educação na idade própria para tal. Nesse ponto, aqueles que se encontram encarcerados tem constitucionalmente afirmada a garantia de acesso à educação.

Cretella (1993) afirma que o art. 208 da Constituição vigente não deixa a menor dúvida a respeito do acesso ao ensino obrigatório e gratuito que o educando, em qualquer grau, cumprindo os requisitos legais, tem o direito público subjetivo, oponível ao Estado, não tendo este nenhuma possibilidade de negar a solicitação, protegida por expressa norma jurídica constitucional cogente.

A posição de Nagib Slaibi Filho é no sentido de que os direitos sociais, que incluem entre eles o direito à educação são oponíveis ao Estado sempre que alguém necessite da prestação deste serviço, no seguinte sentido:

Os direitos sociais, alguns deles declarados sob tal denominação na
Constituição de 1988 , no seu art. 6 o, são múltiplos, de acordo com as
necessidades em uma sociedade diferenciada como a nossa: direito à
educação, à saúde, ao lazer etc. Enquanto os direitos liberais alcançam
dimensão subjetiva ampla, a todos os indivíduos, os direitos sociais
somente alcançam aqueles que necessitam da prestação do serviço.
(SLAIBI FILHO, 1009, p. 303)

Neste sentido, também o encarcerado poderá opor ao Estado seu direito, se este não for garantido no espaço do sistema carcerário, uma vez que depende do agente estatal para ver seu direito social garantido.

Em 1984, há exatos trinta anos, era publicada a "Lei de Execução Penal" (LEP - Lei $n^{\circ}$ 7210/84). Tratando do cumprimento das penas e trazendo consigo preocupação com o sistema prisional e a reintegração do condenado na sociedade. Essa afirmativa se comprova com um olhar em seu artigo primeiro, onde se apresenta o objetivo da lei que é, exatamente, proporcionar condições para a harmônica integração social do condenado e do internado. A Exposição de Motivos 213/83, referente a Lei de Execução Penal, assim esclarece: 
13. Contém o art. $1^{\circ}$ duas ordens de finalidades: a correta efetivação dos mandamentos existentes nas sentenças ou outras decisões, destinados a reprimir e a prevenir os delitos, e a oferta de meios pelos quais os apenados e os submetidos às medidas de segurança venham a ter participação construtiva na comunhão social.

As ações para a reintegração social do condenado, de acordo com o Ministério da Justiça (2014), podem ser entendidas como conjunto de intervenções, sejam: políticas, técnicas ou gerenciais, durante ou após o cumprimento da pena imposta, com o escopo de criar aproximação entre o Estado, as pessoas beneficiadas, bem como com a sociedade, para ampliar a resiliência e reduzir a vulnerabilidade frente ao sistema penal.

Segundo Renato Marcão, em sua obra: "Curso de Execução Penal" (2012), o objetivo da execução penal é, justamente, efetivar as disposições da sentença penal condenatória, mas, para, além desta condição, tem como objetivo proporcionar a integração social do condenado.

Esta integração social tem como fim recuperar os encarcerados, visando seu retorno ao convívio social. Para que seja possível a ressocialização, o tratamento humanitário, com respeito à dignidade da pessoa humana é imprescindível e constam constitucionalmente garantidos.

No cárcere, apenas os direitos atingidos pela sentença penal condenatória podem receber restrições, ou seja, somente aqueles direitos expressamente restringidos na sentença, ou aqueles direitos, cujo exercício mostrem-se conflitantes com a execução da pena imposta naquela sentença, conforme preceitua a lei 7210/84, Lei de Execução Penal (LEP), desta forma:

Art. $3^{\circ}$ Ao condenado e ao internado serão assegurados todos os direitos não atingidos pela sentença ou pela lei.

Parágrafo único. Não haverá qualquer distinção de natureza racial, social, religiosa ou política.

Partindo deste pressuposto, todos os direitos não atingidos pela sentença criminal permanecem a salvo de restrições, devendo ser respeitados pelo Estado, bem como garantidos por ele dentro da prisão. Ao encarcerado, uma vez que conserva seus direitos não atingidos pela sentença penal condenatória, é assegurada assistência pelo Poder Público, que deverá prestá-la da seguinte maneira, prescrita pela Lei de Execução Penal: 
Art. 10. A assistência ao preso e ao internado é dever do Estado, objetivando prevenir o crime e orientar $o$ retorno à convivência em sociedade.

Parágrafo único. A assistência estende-se ao egresso.

Art. 11. A assistência será:

I - material;

II - à saúde;

III -jurídica;

IV - educacional;

$\mathrm{V}$ - social;

$\mathrm{VI}$ - religiosa.

A partir da leitura dos artigos da Lei de Execução Penal transcritos, nota-se que é obrigação do Estado garantir assistência ao encarcerado, justamente pelo fato de que conserva inatingíveis os direitos não restritos na sentença. Esta assistência ampla vem ao encontro dos objetivos da Lei de Execução Penal, para que seja efetivado o tratamento digno, proporcionando a reeducação e ressocialização dos encarcerados. Interessa, neste estudo, apenas a assistência educacional especificamente. Neste sentido, Elionaldo Fernandes Julião esclarece:

\begin{abstract}
O direito à educação escolar como condição inalienável de uma real liberdade de formação (desenvolvimento da personalidade) e instrumento indispensável da própria emancipação (progresso social e participação democrática) é um direito humano essencial para a realização da liberdade e para que esta seja utilizada em prol do bem comum. Dessa forma, ao se abordar a educação para os jovens e adultos (EJA) em situação de privação de liberdade, é importante ter claro que os reclusos, embora privados de liberdade, mantêm a titularidade dos demais direitos fundamentais (integridade física, psicológica e moral). $\mathrm{O}$ acesso ao direito à educação Ihe deve ser assegurado universalmente na perspectiva acima delineada e em respeito às normas que o asseguram (JULIÃO, 2014. p. 148)
\end{abstract}

Desta forma, a assistência educacional, enquanto política pública para orientar o retorno do encarcerado ao meio social, proporcionando-lhe existência digna, atingindo os fins da execução e das propostas de desenvolvimento regional, está prevista no artigo 17 da Lei de Execução Penal. Este prescreve que a assistência compreenderá a instrução escolar e a formação profissional daquele que se encontre em situação de privação de liberdade, por ter cometido uma infração penal.

Para o doutrinador Renato Marcão (2012), a assistência educacional tem como finalidade proporcionar a readaptação à vida social, preparando o preso para o retorno à liberdade. No mesmo sentido, para Mesquita Júnior, em sua obra "Execução Criminal: teoria e prática" (2010), a assistência educacional deve ser 
interpretada em seu sentido mais amplo, compreendendo não somente seu caráter acadêmico, como também seu caráter profissional, bem como seu aspecto social, ético e artístico.

Por determinação da Lei de Execução Penal, o ensino de primeiro grau é obrigatório e integrado ao sistema escolar da Unidade Federativa em que esteja o preso. Já o ensino profissional também é possível, e deverá ser ministrado em nível de iniciação ou aperfeiçoamento técnico. Ainda, há a possibilidade de que as atividades educacionais sejam objeto de convênio com entidades públicas ou particulares, para que estas instalem escolas ou ofereçam cursos especializados dentro do cárcere, visando alcançar o maior número de apenados.

Segundo Julião (2014), esta prescrição legal restringe a oferta da educação no sistema prisional, quando comparada à educação ofertada na modalidade de jovens e adultos, uma vez que, no cárcere, apenas o ensino de primeiro grau é obrigatório, não sendo prevista a possibilidade acesso ao ensino médio e superior.

Em que pese esta posição, a Lei de Execução Penal objetiva alcançar de maneira ampla todos aqueles que se encontram em situação de privação de liberdade, uma vez que determina a integração ao sistema escolar do Estado federado em que este se encontre, mas, também, preocupa-se em permitir convênio com entidades que possam oferecer esta prestação.

Inclusa na política pública educacional, os estabelecimentos penais deverão contar com uma biblioteca, segundo a Lei de Execução Penal. Nela, os encarcerados deverão encontrar livros instrutivos, para a sua formação; recreativos, para ocupar o tempo ocioso no cárcere; e didáticos, que completem ou auxiliem no processo de ensino e aprendizagem daqueles privados de liberdade. Esta biblioteca deverá ser acessível a todos os apenados.

O termo "assistência", utilizado pela Lei de Execução Penal, sugere a prestação de serviços e apoio contínuos aos encarcerados, contando com a atuação de profissionais especializados, o que é dever do Estado e direito do indivíduo com a liberdade restrita. Para incentivar o estudo no cárcere, objetivando a participação massiva dos apenados, regulamentando o processo de ensino e aprendizagem, com vista a reintegração social, outras disposições legais afetam o estudo no sistema prisional. 
Importante esclarecer que a pesquisa não analisou apenas a escolaridade dos autores de homicídio que se encontram encarcerados. Estando em liberdade ou reclusos, os dados foram colhidos e tiveram o mesmo valor, uma vez que, sobrevindo uma condenação, o cumprimento de pena pelo crime de homicídio se dará em estabelecimento penal, de qualquer forma.

\section{PERCURSO METODOLÓGICO}

Na primeira vara criminal da comarca de União da Vitória, Estado do Paraná, foram levantados todos os processos de crime de homicídio, ocorridos durante o ano de 2014. Listados todos os processos, passou-se a verificação do grau de escolaridade de cada autor dos crimes cometidos. Os resultados se encontram na tabela a seguir.

Quadro 1 - Grau de escolaridade dos autores de crime de homicídio

\begin{tabular}{|l|l|l|}
\hline \multicolumn{1}{|c|}{ PROCESSO } & \multicolumn{1}{|c|}{ INFRAÇÃO } & \multicolumn{1}{c|}{ ESCOLARIDADE } \\
\hline $0005894-11.2014 .8 .16 .0174$ & Homicídio Qualificado & Fundamental Incompleto \\
\hline $0008470-74.2014 .8 .16 .0174$ & Homicídio Qualificado & Fundamental Completo \\
\hline $0008258-53.2014 .8 .16 .0174$ & Homicídio Simples & Não consta \\
\hline $0009865-04.2014 .8 .16 .0174$ & Homicídio Simples & Fundamental Completo \\
\hline $0010372-62.2014 .8 .16 .0174$ & Homicídio Simples & Fundamental Completo \\
\hline $0010373-47.2014 .8 .16 .0174$ & Homicídio Simples & Fundamental Completo \\
\hline $0004393-22.2014 .8 .16 .0174$ & Homicídio & Fundamental Incompleto \\
\hline $0005007-27.2014 .8 .16 .0174$ & Homicídio & Fundamental Completo \\
\hline $0000673-47.2014 .8 .16 .0174$ & Homicídio & Fundamental Incompleto \\
\hline $0001010-36.2014 .8 .16 .0174$ & Homicídio & Fundamental Incompleto \\
\hline $0001916-26.2014 .8 .16 .0174$ & Homicídio & Não consta \\
\hline $0002784-04.2014 .8 .16 .0174$ & Homicídio & Não consta \\
\hline $0005340-76.2014 .8 .16 .0174$ & Homicídio & Não consta \\
\hline $0005908-92.2014 .8 .16 .0174$ & Homicídio & Fundamental Completo \\
\hline $0006317-68.2014 .8 .16 .0174$ & Homicídio & Fundamental Incompleto \\
\hline
\end{tabular}

Fonte: Dados da Pesquisa (2015)

Importante destacar que a pesquisa não buscou apenas por autores que se encontrem encarcerados. É possível que estes ainda estejam em liberdade, uma vez que, por se tratar de processos ainda em curso, dado o pouco tempo de transcurso, não há sentença penal condenatória. Desta forma, os autores apontados ainda podem ser absolvidos da acusação, quando do julgamento.

Conforme se verifica, foram encontrados quinze processos pelo crime de homicídio, seja ele na sua forma simples ou qualificada. Em quatro deles não há a 
informação sobre o grau de escolaridade do autor. Nos onze processos restantes há a informação pretendida.

\section{RESULTADOS E DISCUSSÃO}

Em cinco casos, dos onze processos, o suposto autor do crime de homicídio não possui sequer o ensino fundamental completo. Nos demais seis processos, o autor do crime tem o ensino fundamental completo, mas não chegou a iniciar o ensino médio. Numa representação gráfica, tem-se:

Gráfico1: Grau de escolaridade de criminosos.
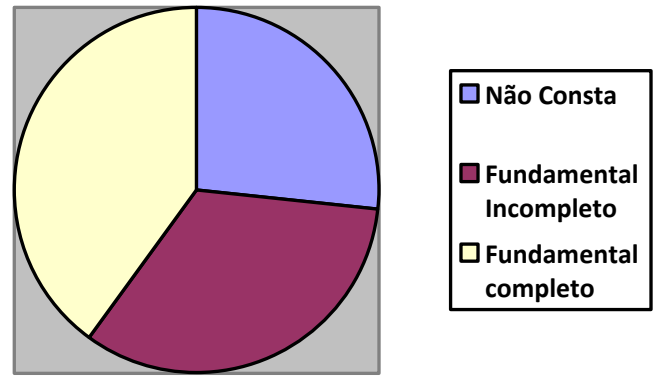

Fonte: Dados da pesquisa (2015)

Como bem se pode ver, nenhum autor de crime de homicídio, ocorrido no ano de 2014, em processos que tramitam na primeira vara criminal da comarca de União da Vitória tem ensino superior, o que revela a necessidade de efetivação das políticas educacionais quando de uma possível sentença penal condenatória e a consequente execução da pena.

\section{VANTAGENS LEGAIS DO ENSINO SUPERIOR PARA CRIMINOSOS}

O ensino superior, quando cursado por aquele acusado de um crime, pode Ihe render benefícios previstos em lei. Em caso de prisão antes de uma sentença penal condenatória transitada em julgado, ou seja, antes do fim do processo, o acusado será recolhido em quartel ou prisão especial, a critério da autoridade judiciária, aquele que for diplomado por qualquer das faculdades superiores da República. Esta previsão está expressa no artigo 295 do Código de Processo Penal. 
Por prisão especial, deve-se entender exclusivamente o recolhimento do acusado em local distinto da prisão comum, ou no mesmo estabelecimento, mas em cela distinta daqueles presos que não o tiverem, enquanto ainda não for condenado definitivamente.

Além do mais, há a previsão, no mesmo artigo do citado dispositivo legal, de que o preso especial, aquele que tem ensino superior completo, não seja transportado juntamente com preso comum, não portador de diploma de ensino superior.

Conforme se verifica nos dados da pesquisa, nenhum daqueles autores de crime poderia ser beneficiado com cela especial, em caso de prisão antes do fim do processo. Acaso forem presos, permanecerão juntamente com os demais criminosos.

É importante esclarecer que, após a condenação definitiva por um crime, não persiste o direito a cela especial. Desta forma, aquele que possui ensino superior completo não terá mais nenhum benefício de tratamento sobre os demais condenados.

Em caso de condenação, o estudo, assistência que deve ser prestada pelo Estado ao preso, incluindo aqui o acesso à Universidade, poderá beneficiá-lo com uma redução no tempo de pena a cumprir.

Auxiliando as políticas educacionais no cárcere, buscando a participação extensiva dos apenados, a Lei de Execução Penal atualmente permite a remição da pena através do estudo.

O termo "remição" tem origem no latim redimere, e significa resgate mediante pagamento, ou reparação, ressarcimento. Não é apenas um perdão da pena, mas uma permuta, uma troca entre Estado e apenado. O encarcerado estuda e o Estado Ihe perdoa parte da pena.

O texto original da Lei de Execução Penal, que vigorou até o ano de 2011, não fazia referência a remição da pena pelo estudo. A possibilidade de perdão de parte da pena dava-se somente pelo trabalho, na razão de um dia de pena remido a cada três dias trabalhados.

A partir do ano de 1984, ano de publicação da Lei de Execução Penal, até 2011 , ano de publicação da lei $12.433 / 11$, doutrina e jurisprudência divergiam sobre 
a possibilidade de estender o benefício da remição àquele encarcerado que dedicasse ao estudo o seu tempo ocioso no cárcere.

Partindo do pressuposto de que a melhor interpretação de uma lei é aquela que melhor favoreça o encarcerado e a sociedade, no sentido da ressocialização do primeiro, por vezes foi permitido pelo Poder Judiciário aos encarcerados a remição de parte da pena através do estudo, mesmo sem expressa disposição legal (MARCÃO, 2012).

Como faltava regulamentação à questão, o Superior Tribunal de Justiça, por meio da Súmula, de enunciado 341, publicada no mês de agosto do ano 2007, dispôs que a freqüência no ensino formal é causa de remição de parte de tempo de execução penal sob o regime fechado ou semiaberto.

Em que pese este enunciado de Súmula, a questão carecia de regulamentação, no sentido de delimitar a forma como se daria a remição da pena através do estudo do encarcerado.

Resolvendo a discussão definitivamente, a lei 12.433/11, regulamenta o artigo 126 da Lei de Execução Penal, prevendo a possibilidade de remição da pena pelo estudo, deixando o artigo com a seguinte redação:

\footnotetext{
Art. 126. O condenado que cumpre a pena em regime fechado ou semiaberto poderá remir, por trabalho ou por estudo, parte do tempo de execução da pena.

$\S 10$ A contagem de tempo referida no caput será feita à razão de:

I - 1 (um) dia de pena a cada 12 (doze) horas de frequência escolar atividade de ensino fundamental, médio, inclusive profissionalizante, ou superior, ou ainda de requalificação profissional - divididas, no mínimo, em 3 (três) dias;

II - 1 (um) dia de pena a cada 3 (três) dias de trabalho.
}

Interpretando a lei de forma extensiva, o doutrinador Renato Marcão, defende a possibilidade das atividades de estudos poderem ser desenvolvidas de forma presencial, ou mesmo na modalidade à distância, desde que certificadas por autoridades educacionais competentes (MARCÃO, 2012).

Desta forma, todo encarcerado que frequente escola de ensino fundamental, médio ou superior, por doze horas, poderá diminuir em um dia a sua pena, pelo instituto da remição, desde que estas doze horas estejam divididas em três dias de estudo. Trata-se de política pública voltada a ressocilização do preso, através do incentivo ao estudo. 
Assim, no caso da pesquisa realizada, se os autores dos crimes forem efetivamente condenados, podem frequentar escola, alterando os dados obtidos, podendo, inclusive, formar-se no ensino superior.

Tal medida lhe possibilitará existência digna, tanto no cárcere, como na sua volta à sociedade, melhorando sua qualidade de vida, auxiliando no processo de desenvolvimento regional.

\section{CONSIDERAÇÕES FINAIS}

O presente artigo se propôs investigar o grau de instrução dos autores de crime de homicídio, que respondem processo perante a primeira vara criminal da comarca de União da Vitória, Estado do Paraná. Além do mais, propôs-se a analisar os benefícios que o ensino universitário concede aos autores de crimes.

Esta análise é relevante diante do fato de que as propostas de desenvolvimento regional devem objetivar a melhoria na qualidade de vida daqueles inseridos na região. Entre estas pessoas que devem sentir a melhora na qualidade de vida com o processo de desenvolvimento, encontram-se os autores de crime, que virão a cumprir pena em estabelecimento penal. Nesta direção, é preciso ter presente que, em que pese o fato de terem cometido crimes, as pessoas inseridas no sistema carcerário conservam seu estado de pessoa humana.

Como se viu, a melhoria da qualidade de vida dá-se, também, pelo tratamento digno de todas as pessoas, incluindo, aqui, aqueles que, por qualquer razão, cometeram crimes. E dignidade se conquista através da eliminação de carências básicas. Desta forma, garantir alimentação, saúde, educação a todos é uma forma de tratamento digno às pessoas, o que, por sua vez, vai ao encontro dos objetivos do desenvolvimento regional, bem como da execução penal.

Ao longo desta pesquisa, evidencia-se como políticas educacionais que afetam o sistema carcerário, a obrigatoriedade da oferta do ensino regular dentro do cárcere, que deverá atender a todos, considerando, ainda, as peculiaridades daqueles educandos do sistema carcerário, já que trata-se de público jovem e adulto, privado de liberdade, bem como considerando as peculiaridades do espaço em que deverá ser ofertada a educação, buscando profissionais qualificados para tanto, em um ambiente de ensino adequado. 
Com a análise dos dados obtidos na pesquisa, foi possível verificar que os autores de crime de homicídio que respondem processo naquela vara não iniciaram sequer o ensino médio, estando muito distantes do ensino universitário.

Além do mais, foi possível identificar que o diploma de conclusão de curso em instituição de ensino superior permite ao autor de crime, quando preso provisoriamente, sem ter uma sentença penal condenatória transitada em julgado, ter direito a cela especial, mantendo-o afastado dos demais autores de crime.

Outro benefício que a legislação oferece àquele que estuda, inclusive em instituição de ensino superior, enquanto cumpre pena, é o instituto da remição pelo estudo, que por muitos anos não foi legalmente regulamentado, prevalecendo o entendimento jurisprudencial de sua possibilidade. Alterando esta situação, desde o ano de 2011, por disposição legal, a remição pelo estudo foi implantada e devidamente regulamentada.

Em que pese os benefícios que o ensino universitário pode conceder àqueles que cometem crimes, o nível de escolarização daqueles que se encontram encarcerados ainda é baixo, conforme os dados disponibilizados pelo Ministério da Justiça e trazidos para este artigo, bem como os dados levantados durante a investigação na primeira vara criminal da comarca de União da Vitória, Estado do Paraná. Tal situação demonstra a necessidade de efetivarem-se as políticas educacionais, dever do Estado, carecendo de atenção do Poder Público e da Sociedade em geral.

\section{REFERÊNCIAS}

BARROS, Flávio Augusto Monteiro de. Direito penal: parte geral. 7.ed. São Paulo: Saraiva, 2009. v. 1.

BITENCOURT. Cezar Roberto. Tratado de direito penal: parte geral. 11. ed. São Paulo: Saraiva, 2007. v. 1.

BOISIER, S. Descodificando EI Desarrollo Del Siglo Xxi: Subjetividad, Complejidad, Sinapsis, Sinergía, Recursividad, Liderazgo, Y Anclaje Territorial. In: Semestre Económico, Medellín, Colombia, v. 13, n. 27, p. 11-37, jul./dic. 2010, 2010. 
BRASIL. Código Penal; Processo Penal e Constituição Federal. Obra coletiva de autoria da Editora Saraiva com a colaboração de Antonio Luiz de Toledo Pinto, Márcia Cristina Vaz dos Santos Windt e Lívia Céspedes. 5.ed. São Paulo: Saraiva, 2009.

. Código de Processo Penal. Disponível em:

<http://www.planalto.gov.br/ccivil_03/decreto-lei/del3689compilado.htm>. Acesso em: fev. 2015.

. Constituição da República Federativa do Brasil. Disponível em:

<http://www.planalto.gov.br/ccivil_03/constituicao/constituicao.htm>. Acesso em: 06 ago. 2014.

. Decreto-Lei $\mathbf{n}^{0}$ 7626/11. Disponível em:

<http://www.planalto.gov.br/ccivil_03/_Ato2011-2014/2011/Decreto/D7626.htm>. Acesso em: 07 ago. 2014.

. Lei de Execução Penal. Disponível em:

<http://www.planalto.gov.br/ccivil_03/leis/l7210.htm>. Acesso em: 06 ago. 2014.

. Ministério da Justiça. Exposição de Motivos 213/1983. Disponível em:

<http://portal.mj.gov.br/services/DocumentManagement/FileDownload.EZTSvc.asp? DocumentID=\%7BC116F62C-19FB-4F25-8625-

E6D3D415537D\%7D\&ServicelnstUID=\%7B4AB01622-7C49-420B-9F7615A4137F1CCD\%7D>. Acesso em: 12 ago. 2014.

. Relatórios Estatísticos. Disponível em:

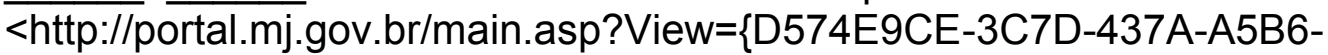

22166AD2E896\}\&BrowserType=NN\&LangID=pt-

br\&params=itemID\%3D\%7BC37B2AE9-4C68-4006-8B16-

24D28407509C\%7D\%3B\&UIPartUID=\%7B2868BA3C-1C72-4347-BE11-

A26F70F4CB26\%7D>. Acesso em: 06 ago. 2014.

. Superior Tribunal de Justiça. Súmula 341. Disponível em:

<http://www.stj.jus.br/SCON/sumulas/enunciados.jsp?\&b=SUMU\&p=true\&t=\&l=10\&i $=171>$. Acesso em: 07 ago. 2014.

CAPEZ, Fernando. Curso de direito penal: parte geral. 14. ed. São Paulo: Saraiva, 2010.

CRETELLA Jr., José. Comentários à Constituição Brasileira de 1988. 2.ed. Rio de Janeiro: Forense, 1993. v. 8.

DALLABRIDA, Valdir Roque. Desenvolvimento regional: por que algumas regiões se desenvolvem e outras não? Santa Cruz do Sul: EDUNISC, 2010. 
DAMASCENO, Adriana Simonassi. et al. Experiências Formativas no Sistema Prisional: Inclusão Social e Ressocialização. Revista História e Diversidade, v. 2, n. 1, p. 173-186, 2013. Disponível em: <http://www.unemat.br/revistas/ historiaediversidade/docs/edicao2013/adriana_simonassi_damasceno,_experiencias _formativas_no_sistema_prisional.pdf: Acesso em: 11 ago. 2014.

DIAS, Adelaide Alves. Da educação como direito humano aos direitos humanos como princípio educativo. Educação em direitos humanos: fundamentos teóricometodológicos. João Pessoa: Editora Universitária, 2007.

DUARTE, Clarisse Seixas. Direito Público Subjetivo e Políticas Educacionais. São Paulo em Perspectiva, v. 18, n. 2, p. 113-118, 2004. Disponível em: <http://www.scielo.br/pdf/spp/v18n2/a12v18n2.pdf>. Acesso em: 06 ago. 2014.

ESTEFAN, André. Direito penal: parte geral. São Paulo: Saraiva, 2010. v.1.

JULIÃO, Elionaldo Fernandes. A Ressocialização por Meio do Estudo e do Trabalho no Sistema Penitenciário Brasileiro. Em Aberto, Brasília, v. 24, n. 86, p. 141-155. 2011. Disponível em: <http://emaberto.inep.gov.br/index.php/ emaberto/article/viewFile/2583/1772> Acesso em: 11 ago. 2014.

MARCÃO, Renato. Curso de execução penal. 10 ed. São Paulo: Saraiva, 2012.

MESQUITA JÚNIOR, Sidio Rosa de. Execução criminal: teoria e prática. 6.ed. São Paulo: Atlas, 2010.

NUNES, Adeildo. Da execução penal. 2.ed. Rio de Janeiro: Forense, 2012.

OLIVEIRA, Romualdo Portela de. O direito à educação na Constituição Federal de 1988 e seu restabelecimento pelo sistema de Justiça. Revista Brasileira de Educação, v. 11, p. 61-74, 1999.

PIERANGELI, José Henrique; ZAFFARONI, Eugênio Raul. Manual de direito penal brasileiro: parte geral. 7. ed. São Paulo: Revista dos Tribunais, 2007. v. 1.

PIERANGELI, José Henrique. Manual de direito penal brasileiro: parte especial. 2.ed. São Paulo: Revista dos Tribunais, 2007. v. 2.

SIEDENBERG, Dieter Rugard. A gestão do desenvolvimento: ações e estratégias entre a realidade e a utopia. In: Desenvolvimento regional: abordagens interdisciplinares. Santa Cruz do Sul: EDUNISC, 2008.

SLAIBI FILHO, Nagib. Direito constitucional. 3.ed. Rio de Janeiro: Forense, 2009.

TAVARES, André Ramos. Curso de direito constitucional. 12.ed. São Paulo: Saraiva, 2014. 
TORO, Bernardo. Códigos da modernidade. Colômbia, 2007. Disponível em: $<$ http://www.ufrn.br/sites/engenhodesonhos/mediateca/artigos/codigosdamodernidad e.pdf>. Acesso em: 06 ago. 2014.

Artigo recebido em: 06/10/2015

Artigo aprovado em: 23/05/2016 